\title{
SIMULTANEOUS MEASUREMENTS OF INDOOR RADON, RADON-THORON PROGENY AND HIGH-RESOLUTION GAMMA SPECTROMETRY IN GREEK DWELLINGS
}

\author{
A. Clouvas*, S. Xanthos and M. Antonopoulos-Domis \\ Nuclear Technology Laboratory, Department of Electrical and Computer Engineering, \\ Aristotle University of Thessaloniki, GR-54124 Thessaloniki, Greece
}

Received April 27 2005, revised September 62005 and October 26 2005, accepted October 312005

\begin{abstract}
Simultaneous indoor radon, radon-thoron progeny and high-resolution in situ gamma spectrometry measurements, with portable high-purity Ge detector were performed in $\mathbf{2 6}$ dwellings of Thessaloniki, the second largest town of Greece, during March 2003-January 2005. The radon gas was measured with an AlphaGUARD ionisation chamber (in each of the 26 dwellings) every $10 \mathrm{~min}$, for a time period between 7 and $10 \mathrm{~d}$. Most of the values of radon gas concentration are between 20 and $30 \mathrm{~Bq} \mathrm{~m} \mathrm{~m}^{-3}$, with an arithmetic mean of $34 \mathrm{~Bq} \mathrm{~m}{ }^{-3}$. The maximum measured value of radon gas concentration is $516 \mathrm{~Bq} \mathrm{~m}$. The comparison between the radon gas measurements, performed with AlphaGUARD and short-term electret ionisation chamber, shows very good agreement, taking into account the relative short time period of the measurement and the relative low radon gas concentration. Radon and thoron progeny were measured with a SILENA (model 4s) instrument. From the radon and radon progeny measurements, the equilibrium factor $F$ could be deduced. Most of the measurements of the equilibrium factor are within the range $0.4-0.5$. The mean value of the equilibrium factor $F$ is $0.49 \pm 0.10$, i.e. close to the typical value of 0.4 adopted by UNSCEAR. The mean equilibrium equivalent thoron concentration measured in the 26 dwellings is $\mathrm{EEC}_{\text {thoron }}=1.38 \pm 0.79 \mathrm{~Bq} \mathrm{~m}$. The mean equilibrium equivalent thoron to radon ratio concentration, measured in the 26 dwellings, is $0.1 \pm 0.06$. The mean total absorbed dose rate in air, owing to gamma radiation, is $58 \pm 12 \mathrm{nGy} \mathrm{h}^{-1}$. The contribution of the different radionuclides to the total indoor gamma dose rate in air is $38 \%$ due to ${ }^{40} \mathrm{~K}, 36 \%$ due to thorium series and $26 \%$ due to uranium series. The annual effective dose, due to the different source terms (radon, thoron and external gamma radiation), is $1.05,0.39$ and $0.28 \mathrm{mSv}$, respectively.
\end{abstract}

\section{INTRODUCTION}

About one-half of the effective dose from natural sources is estimated to be delivered by inhalation of the short-lived radon decay products ${ }^{(1)}$. Owing to this fact, radon is the most 'popular' subject of studies on environmental radioactivity. Largescale radon surveys have been performed in many countries $^{(1)}$. In Greece, the relatively larger radon survey $^{(2)}$ has been carried out from 1995 to 1998 , using etched track detectors in 1277 dwellings. According to the results obtained, it was found that only a small percentage of dwellings appeared to have annual average radon levels $>400 \mathrm{~Bq} \mathrm{~m}^{-3}$, which is the action level proposed by the European Union. Although the exposure to radon is mainly from the inhalation of the short-lived radon decay products and not from the radon gas itself, most large surveys are of radon gas concentration $C_{\mathrm{Rn}}$. Direct measurements of the concentrations of all short-lived radon decay products are difficult and limited. They are estimated from considerations of equilibrium (or disequilibrium) between radon and the decay products. The parameter of interest is the equilibrium equivalent concentration (EEC) of

*Corresponding author: clouvas@eng.auth.gr radon, $\mathrm{EEC}_{\mathrm{Rn}}$, and the two quantities $\left(\mathrm{EEC}_{\mathrm{Rn}}\right.$ and $C_{\mathrm{Rn}}$ ) are related through the equilibrium factor $F$, defined by the expression

$$
\begin{aligned}
& F=\frac{\mathrm{EEC}_{\mathrm{Rn}}}{C_{\mathrm{Rn}}}, \\
& \mathrm{EEC}_{\mathrm{Rn}}=0.105 C_{1}+0.515 C_{2}+0.380 C_{3},
\end{aligned}
$$

where $C_{1}, C_{2}$ and $C_{3}$ are the activity concentrations of the radon decay progeny namely ${ }^{218} \mathrm{Po},{ }^{214} \mathrm{~Pb}$ and ${ }^{214} \mathrm{Bi}$, respectively. Similarly, the EEC of thoron $\left({ }^{220} \mathrm{Rn}\right), \mathrm{EEC}_{\text {thoron }}$, is given by

$$
\mathrm{EEC}_{\text {thoron }}=0.913 C_{1}+0.087 C_{2},
$$

where $C_{1}, C_{2}$ are the activity concentrations of the thoron decay progeny namely ${ }^{212} \mathrm{~Pb}$ and ${ }^{212} \mathrm{Bi}$, respectively.

Recent determinations of the equilibrium factor for radon indoors confirm the typical value ${ }^{(1)}$ of 0.4 . Indoor measurements show a range from 0.1 to 0.9 , but most are within $30 \%$ of the typical value of 0.4 . In a recent study ${ }^{(3)}$ the time variation of the equilibrium factor $F$ was measured every $4 \mathrm{~h}$, in the Nuclear Technology Laboratory of the Aristotle University of Thessaloniki during October 1998April 1999. The time variation of the equilibrium 


\section{A. CLOUVAS ET AL.}

factor $F$ was relatively small (within a range of $23 \%$ for a confidence level of $90 \%$ ). In the same study, the radon equilibrium factor was measured in 25 apartments randomly distributed in Thessaloniki, the second largest town of Greece. The mean value of the equilibrium factor $F$ was $0.47 \pm 0.09$, close to the typical value of 0.4 adopted by $\operatorname{UNSCEAR}^{(1)}$.

Available data of thoron $E E C$ are generally results of a few, short-term measurements and are thus far less representative than the results of radon ${ }^{(1)}$. For Greece, as far as we know, there is no systematic study of indoor $\mathrm{EEC}_{\text {thoron. }}$.

In the present work, simultaneously indoor radon, radon-thoron progeny and high-resolution in situ gamma spectrometry measurements in 26 Greek dwellings are performed. The motivation to perform such measurements is

- The lack of thoron progeny measurements in Greek dwellings.

- Although measurements of thoron in indoor air are limited, most investigations have reported both the radon and thoron EECs, so some generalisations for the derived ratios can be made ${ }^{(1)}$. In the present work, from the simultaneous measurement of radon and thoron progeny the above aforementioned ratio could be deduced.

- The determination of the equilibrium factor (Equation 1) is important for the determination of the effective dose due to radon.

- The use of different experimental approaches for indoor radon determination is important for the comparison of the different techniques in real conditions.

- In a recent study(4), the possible correlation between indoor radon and indoor gamma dose rates deduced by in situ gamma spectrometry measurements, with portable high-purity Ge (HPGe) detector, was investigated. No correlation was found between indoor gamma dose rate due to uranium series and indoor radon, for ground and first floor apartments. For upper floor apartments (above second floor) a weak correlation was observed. In the present work the possible correlation between thoron progeny and indoor gamma dose rate, due to thorium series, is investigated.

\section{MATERIALS AND METHODS}

Simultaneous indoor radon, radon-thoron progeny and high resolution in situ gamma spectrometry measurements, with portable HPGe detector, were performed in 26 dwellings of Thessaloniki, during March 2003-January 2005. The duration of the radon, radon-thoron progeny measurement in each dwelling was from 7 to $10 \mathrm{~d}$. The dwellings were common apartments in standard Greek buildings (made of fired clay brick and reinforced concrete), randomly distributed in Thessaloniki.

Radon gas measurements were performed with two types of experimental devices:

(1) With a portable, passive, real-time ionisation chamber (AlphaGUARD). Its sensitive volume is 0.554 litre. Through the application of three different pulse-shaping networks, in combination with three separate analog-digital converter (ADC) channels, different types of information can be extracted from the chamber signal. The sensitivity of the instrument is 0.05 counts $\mathrm{min}^{-1}$ per $\mathrm{Bq} \mathrm{m}^{-3}$. It also has the capability of measuring temperature, relative humidity and barometric pressure. The measurement cycle time was $10 \mathrm{~min}$.

(2) With the electret ionisation chamber ${ }^{(5)}$ which is a small, passive integrating device designed for short-term, or long-term, exposures. The device consists of a $200 \mathrm{ml}$ conducting plastic chamber containing an electret. Radon gas passively diffuses into the chamber through filtered inlets, and the alpha particles emitted by the decay process of radon ionise air molecules. Ions produced inside the chamber volume are collected onto the surface of the electret, causing a reduction of its surface charge. The electret voltage decreases in proportion to the integrated radon concentration. A voltage reader is used to measure the electret surface voltage. The experimental uncertainty of radon concentration measurements, using electret ionisation chambers, is better than $10 \%$.

Although the most popular counting technique for radon progeny measurements is by gross alpha counting ${ }^{(6)}$, for the present work the alpha spectroscopy method was selected, which is a more complex and costly method than the previous one. It yields more precise measurements, owing to its highspectral resolution. Alpha spectrometry can provide measurements of radon progeny concentrations of $<20 \mathrm{~Bq} \mathrm{~m}^{-3}$, with a precision of better than $20 \%{ }^{(6)}$. In addition thoron daughter concentration can be deduced, owing to the different alpha energies of radon and thoron progeny. Radon and thoron progeny measurements were not performed continuously, as for radon gas, but every $4 \mathrm{~h}$. In each measurement the following steps were performed. First air ( 3 litres $\mathrm{min}^{-1}$ ) was pumped for $15 \mathrm{~min}$ through a filter. The sampling filter faces a silicon surface barrier detector. The energies of interest are separated by a four channel discriminator. The energy windows are set as follows: first window 4.92-6.20 MeV, second window 6.20-6.75 MeV, third window 6.75-8.15 $\mathrm{MeV}$ and fourth window 8.15-9.8 MeV. Integral counts from each channel, 
during three successive counting periods of $20 \mathrm{~min}$ each (with a time interval of $10 \mathrm{~min}$ between the first and second counting period and $130 \mathrm{~min}$ between the second and third counting period), are stored in eight counters (the four windows of the first counting period; the second, third, and fourth window of the second counting period; and the fourth window for the third counting period). These data are then introduced to Martz-Kerr equations ${ }^{(7)}$ to give radon-thoron daughters concentrations and the equilibrium equivalent radon and thoron concentration. The air sampling and measurement device (SILENA model 4s) allows the complete measurement cycle to be performed automatically, without any intervention from the operator. This feature eliminates operator errors that are often encountered in manual procedures. Moreover, the alpha counting is carried out under vacuum, which is important for the precision of the measurements. The air filter was changed once per day in different time periods (morning, afternoon and night). The change of the filter is mandatory for the thoron progeny measurement, owing to the build-up in the filter of ${ }^{212} \mathrm{~Pb}$ (half-life $10.6 \mathrm{~h}$ ). For thoron progeny, only the first measurement with each new filter was taken into account.

The portable Ge detector, used for the in situ gamma spectrometry measurements, is a HPGe coaxial cylinder $63 \mathrm{~mm}$ in diameter and $55.5 \mathrm{~mm}$ in length, with an efficiency for a point source at $25 \mathrm{~cm}$ at $1.33 \mathrm{MeV}$ of $40 \%$ relative to a $7.6 \times$ $7.6 \mathrm{~cm} \mathrm{NaI(Tl)}$ crystal. It is mounted in a small liquid nitrogen cryostat that features in all-attitude capability. The spectrum is collected in a portable multichannel analyser, which also provides high voltage and preamplifier power to the detector. The multichannel analyser is connected to a portable computer, where the gamma spectra can be stored and analysed with appropriate software. The in situ measurements were performed with a downward, tripod-mounted facing detector at $1 \mathrm{~m}$ above ground. The duration of each measurement was $1000 \mathrm{~s}$. The methodology used for the derivation of the indoor gamma dose rates, from the in situ indoor gamma ray spectra, has been explicitly described in previous publications ${ }^{(8,9)}$.

\section{RESULTS AND DISCUSSION}

\section{Radon gas measurements}

The radon gas was measured with the AlphaGUARD (in each of the 26 dwellings), every $10 \mathrm{~min}$ for a time period between 7 and $10 \mathrm{~d}$. Figure 1 presents the frequency distribution of the radon gas concentration in the 26 dwellings. Most of the values of radon gas concentration are between 20 and $30 \mathrm{~Bq} \mathrm{~m}{ }^{-3}$ with an arithmetic mean of $34 \mathrm{~Bq} \mathrm{~m}^{-3}$. The maximum measured value of radon gas concentration is $516 \mathrm{~Bq} \mathrm{~m}^{-3}$.

The radon gas was also measured with integrated passive devices. Owing to the relative short period of measurement in each dwelling (7-10 d), the shortterm electret ionisation chamber ${ }^{(5)}$ with a $200 \mathrm{ml}$ conducting plastic chamber was used. In each dwelling two electret ionisation chambers were installed.

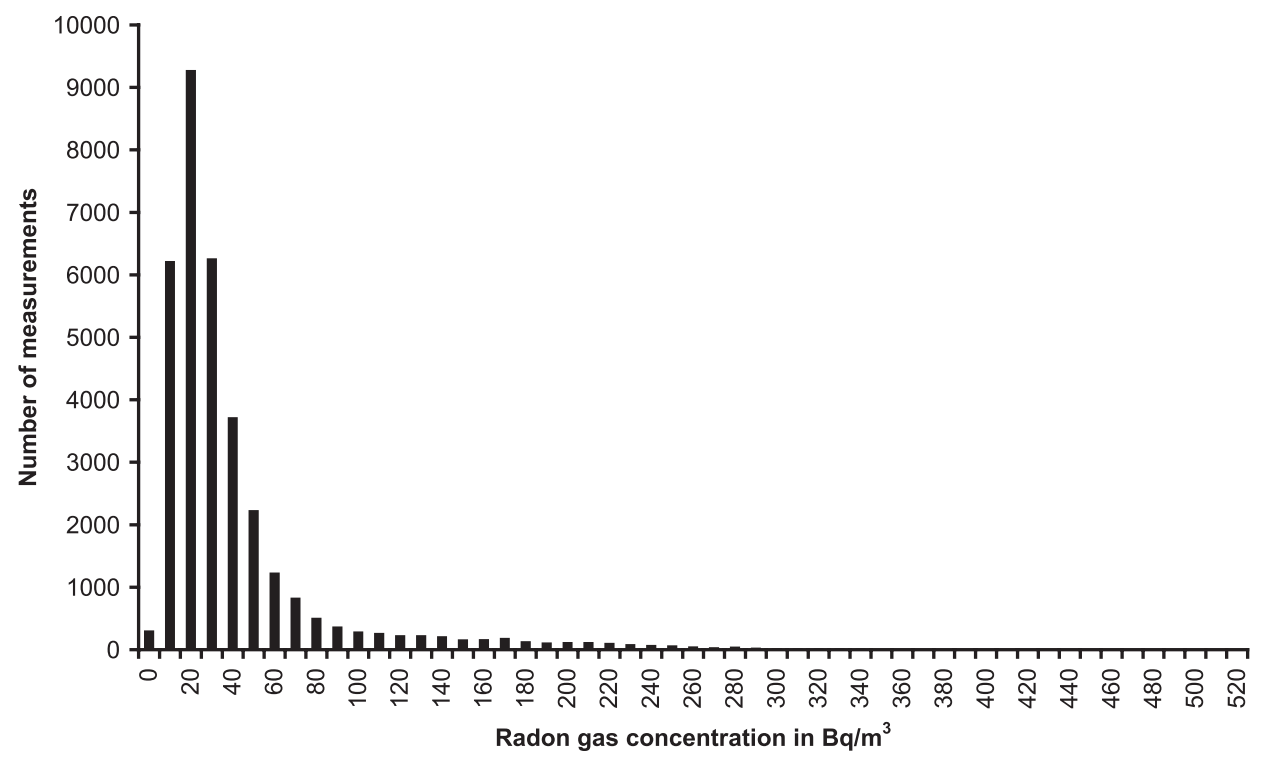

Figure 1. Frequency distribution of the radon gas concentration. 


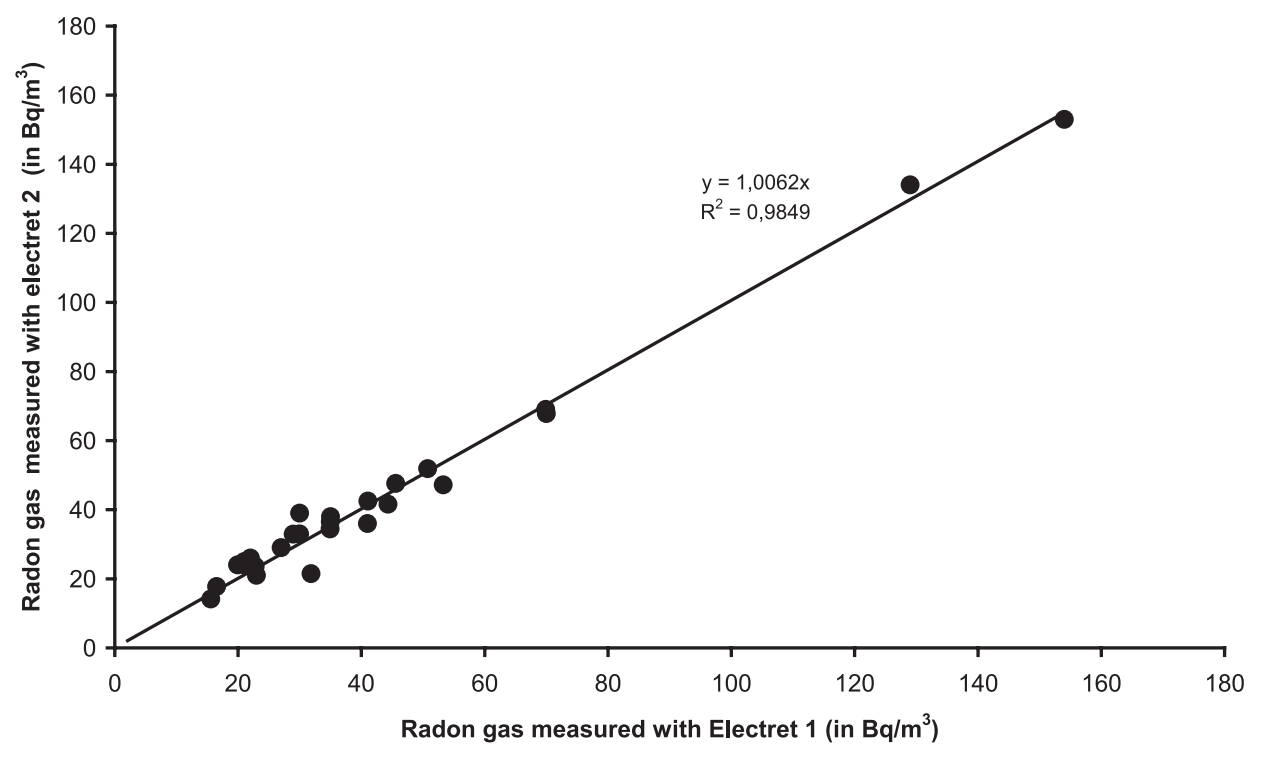

Figure 2. Correlation between the radon gas concentrations measured by the two electrets.

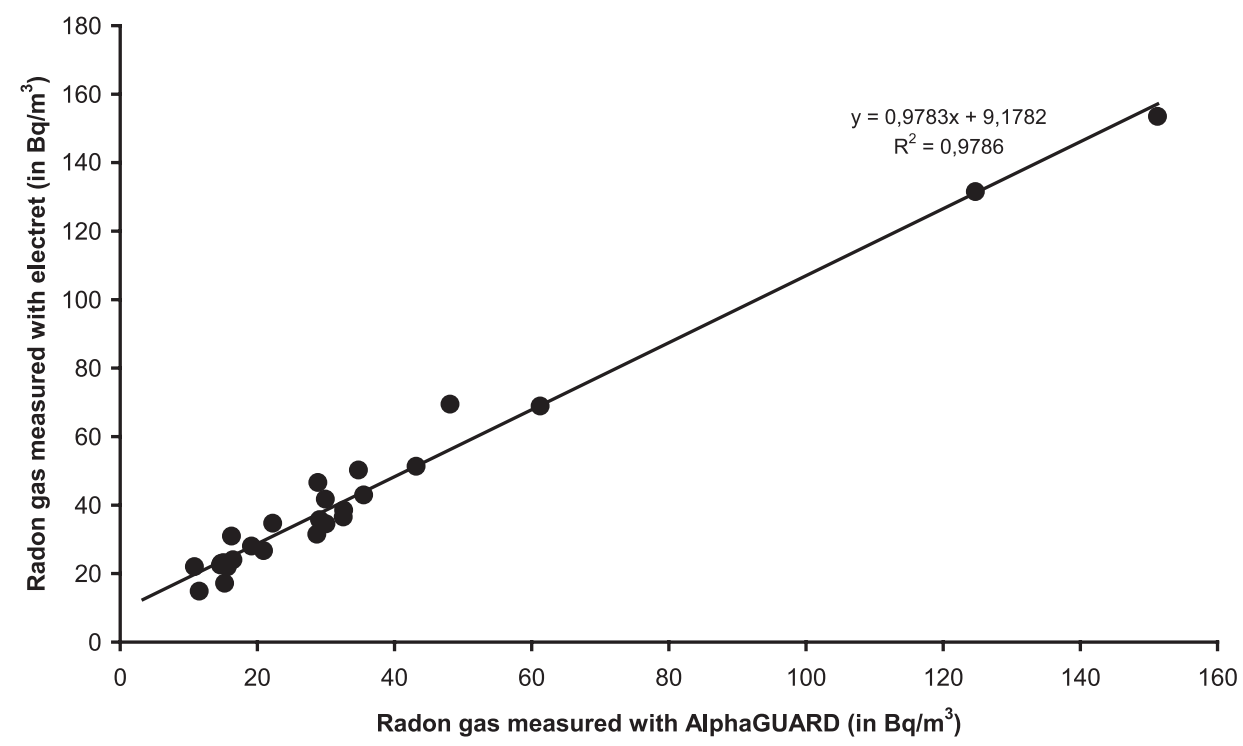

Figure 3. Correlation between the radon gas measurements by the two electrets (mean value) and the AlphaGUARD.

The very good correlation of the radon gas concentration, measured by the two electrets, is shown in Figure 2.

The correlation between the radon gas concentration measured with the AlphaGUARD and the mean value of the two short-term electret ionisation chambers is shown in Figure 3.

As shown in Figure 3, the correlation between the radon gas concentration, measured by the two instruments (AlphaGUARD and electret), is very good (correlation factor $\left.R^{2}=0.98\right)$. However, the measurements performed with the electrets seems to have a constant shift of $\sim 9 \mathrm{~Bq} \mathrm{~m}^{-3}$ in comparison with the measurements performed with the AlphaGUARD. Environmental radon monitors that incorporate electret detectors, are confounded by background gamma radiation, which may cause the electret to discharge. In order to minimise systematic bias, when using a radon detector (electret) that exhibits gamma sensitivity, the measurement results 


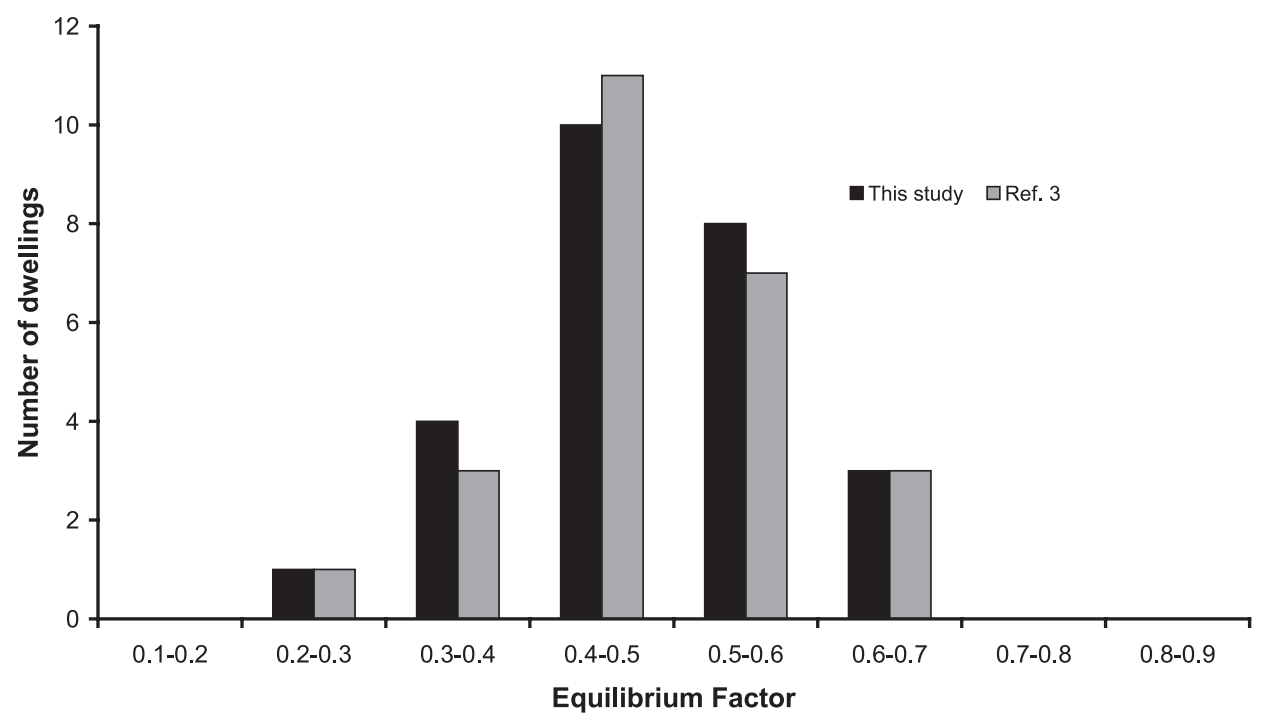

Figure 4. Frequency distribution of the equilibrium factor measured in the 26 dwellings. In the same plot the frequency distribution of the equilibrium factor measured previously ${ }^{3}$ in 25 dwellings of Thessaloniki is also shown.

must be appropriately corrected, especially when measuring radon in areas of high-gamma background. These gamma background corrections become significant when performing long-term monitoring of radon at low concentrations, using electret ion chamber detectors, since the discharge of the electret, owing to the cumulative gamma background, may be of the same magnitude as the discharge owing to radon. Although, in the present work, background gamma corrections were made by multiplying the measured background gamma exposure with a constant conversion factor given by the manufacturer, it has been shown ${ }^{(10)}$ that doing so, introduces an error ranging up to $20 \%$, especially in high background areas. In our measurements, even if there is no high background areas, the fact that the radon concentration is low can explain the small observed shift between AlphaGUARD and electret ionisation chambers. Even if the use of single electrets to measure radon in mixed radiation fields became a common practice, one must have always in mind, that in radioprotection it is important to measure selectively the alphas and the gammas respectively, especially because we are dealing with two types of radiation, with big difference in the quality factor.

\section{Radon progeny measurements}

Radon progeny was measured in each dwelling, every $4 \mathrm{~h}$, for a period of 7-10 d, simultaneously with the radon gas measurements. From Equation 1 the radon equilibrium factor $F$ could be easily deduced, for each of the 26 dwellings. The fact that the equilibrium factor was not measured simultaneously in the 26 dwellings is not an important issue, as the time dependence of the mean weekly value of radon equilibrium factor was found ${ }^{(3)}$ to be relatively small. The frequency distribution of the equilibrium factor, measured in the 26 dwellings, is shown in Figure 4.

In the same figure the frequency distribution of the equilibrium factor, measured previously ${ }^{(3)}$ in 25 dwellings of Thessaloniki, is also shown. The distributions of the two datasets are quite similar. This fact probably means that the distribution of the equilibrium factor shown in Figure 4 is representative for the town of Thessaloniki and not only for the 26 dwellings measured in the present work. Most of the measurements of the equilibrium factor are within the range $0.4-0.5$. The mean value of the equilibrium factor $F$ is $0.49 \pm 0.10$, close to the value $0.47 \pm 0.09$, measured previously ${ }^{(3)}$ and close to the typical value of 0.4 adopted by UNSCEAR ${ }^{(1)}$.

\section{Thoron progeny measurements}

Thoron progeny was measured in each dwelling every $4 \mathrm{~h}$ for a period of $7-10 \mathrm{~d}$, simultaneously with the radon progeny measurements. The air filter of the air sampling and measurement device (SILENA model 4s) was changed once per day in different time periods (morning, afternoon and night). The change of the filter is mandatory for the thoron progeny measurement, owing to the build-up (in the filter) of ${ }^{212} \mathrm{~Pb}$ (half-life $10.6 \mathrm{~h}$ ). Figure 5 presents a typical time dependence of the EEC of 


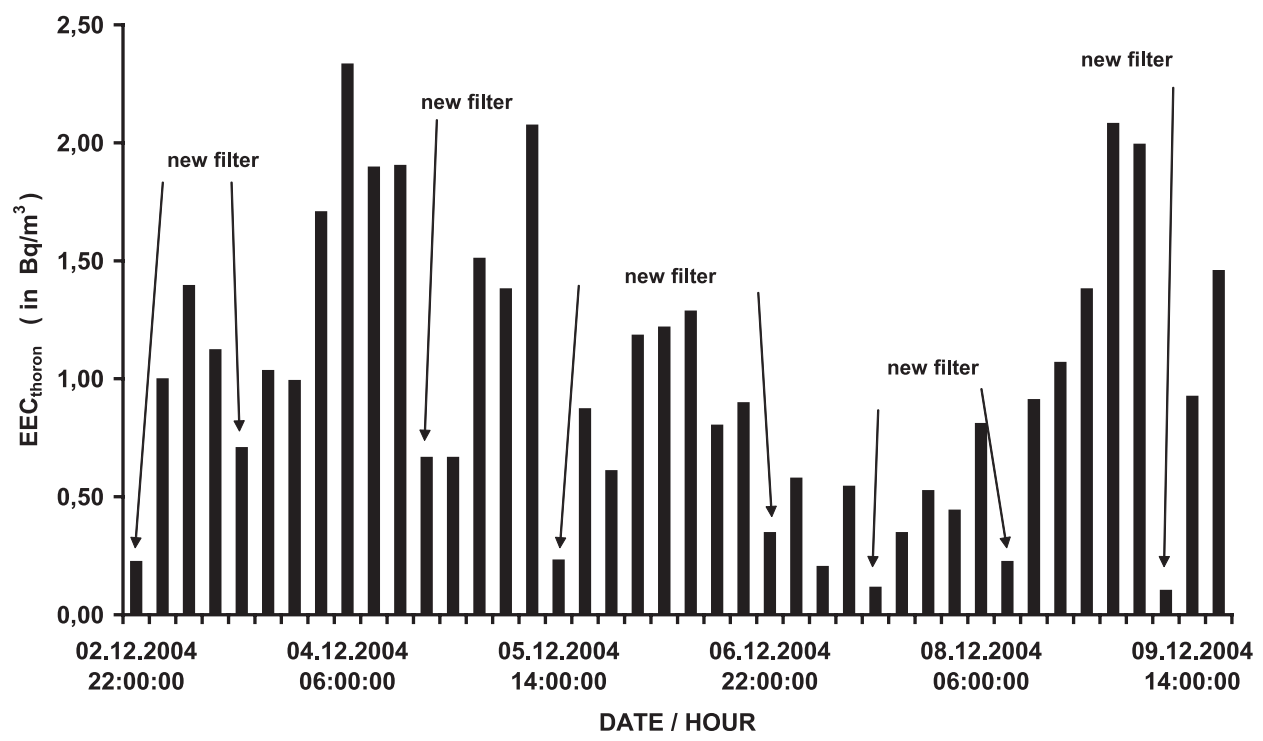

Figure 5. Typical time dependence of the equilibrium equivalent thoron concentration in a dwelling. It is clearly observed the decrease in $\mathrm{EEC}_{\text {thoron }}$ with every new filter. For $\mathrm{EEC}_{\text {thoron }}$ determination, only the first measurement with each new filter was taken into account.

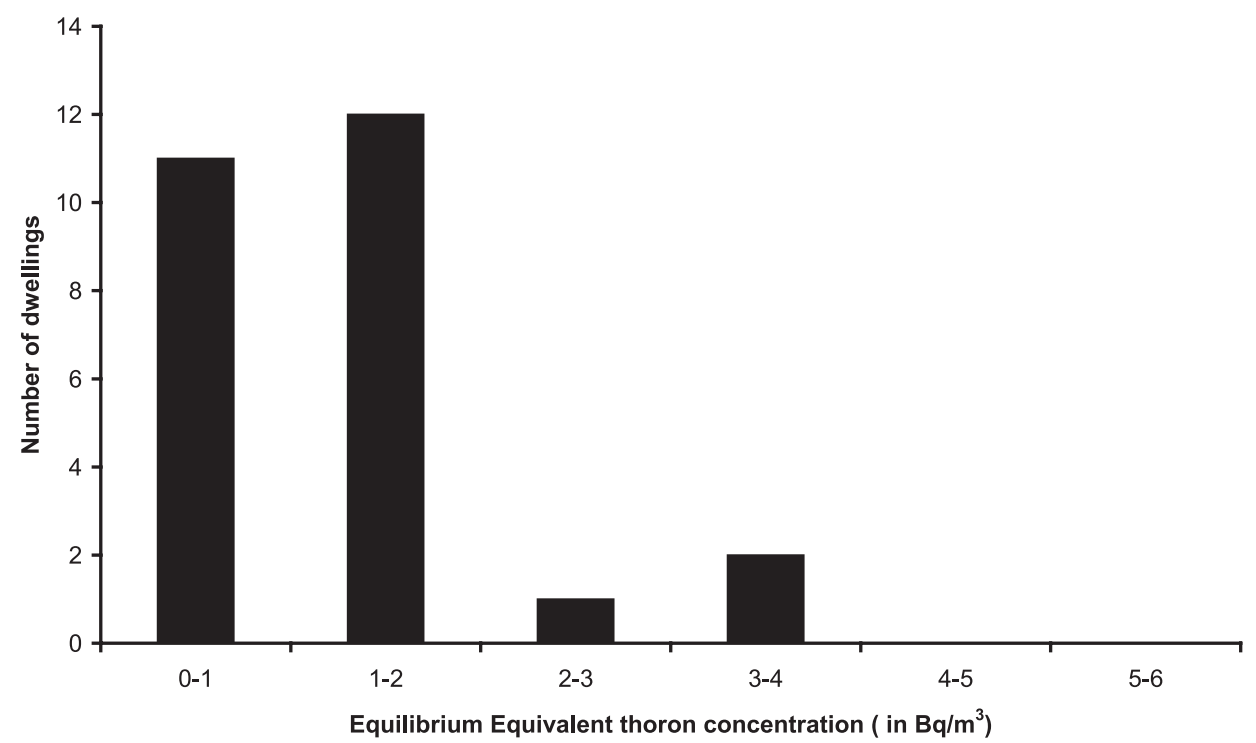

Figure 6. Frequency distribution of the equilibrium equivalent thoron concentration measured in the 26 dwellings.

thoron, $\mathrm{EEC}_{\text {thoron }}$ in a dwelling. The decrease in $\mathrm{EEC}_{\text {thoron }}$ with every new filter can be clearly observed.

For the determination of $\mathrm{EEC}_{\text {thoron }}$ only the first measurement, with each new filter was considered. Taking into account that the filter was changed once a day (in different time periods), the mean $\mathrm{EEC}_{\text {thoron }}$ of each dwelling was a mean value of $\sim 7-10$ measurements. Figure 6 shows the frequency distribution of the $\mathrm{EEC}_{\text {thoron, }}$ measured in the 26 dwellings. The mean equilibrium equivalent thoron concentration measured in the 26 dwellings is EEC $_{\text {thoron }}=$ $1.38 \pm 0.79 \mathrm{~Bq} \mathrm{~m}^{-3}$. This value is slightly higher than the mean values of $\mathrm{EEC}_{\text {thoron }}\left(0.3-1.1 \mathrm{~Bq} \mathrm{~m}^{-3}\right)$ 


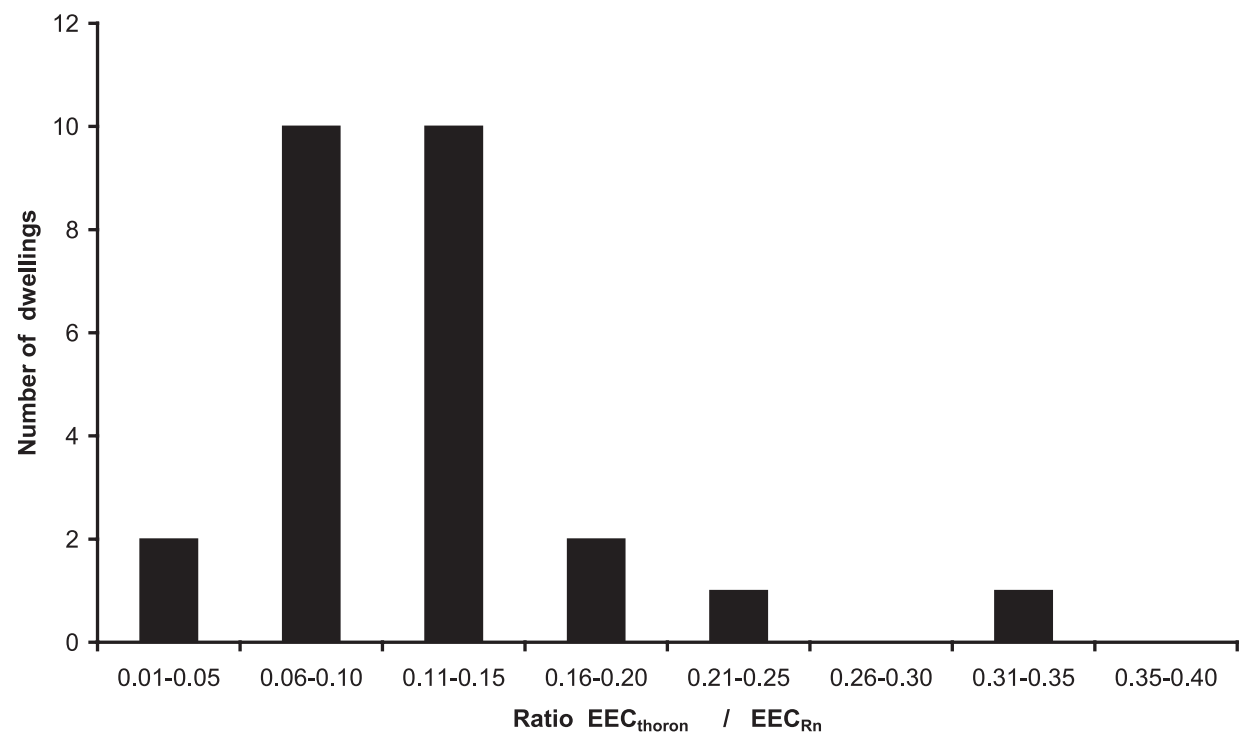

Figure 7. Frequency distribution of the equilibrium equivalent thoron to radon ratio concentration measured in the 26 dwellings.

Table 1. Arithmetic mean, minimum and maximum values of absorbed gamma dose rate in air due to uranium series, thorium series, ${ }^{40} \mathrm{~K}$ and the sum of them as deduced from 26 indoor in situ gamma spectrometry measurements in Thessaloniki.

\begin{tabular}{|c|c|c|c|c|c|c|c|c|c|}
\hline & \multirow[t]{2}{*}{ Dwellings } & \multicolumn{2}{|c|}{$\begin{array}{l}\text { Uranium series } \\
\qquad\left(\mathrm{nGy} \mathrm{h}^{-1}\right)\end{array}$} & \multicolumn{2}{|c|}{$\begin{array}{l}\text { Thorium series } \\
\left(\mathrm{nGy} \mathrm{h}^{-1}\right)\end{array}$} & \multicolumn{2}{|c|}{${ }^{40} \mathrm{~K}\left(\mathrm{nGy} \mathrm{h}{ }^{-1}\right)$} & \multicolumn{2}{|c|}{ Total $\left(\mathrm{nGy} \mathrm{h} \mathrm{h}^{-1}\right)$} \\
\hline & & Mean & Range & Mean & Range & Mean & Range & Mean & Range \\
\hline This work & 26 & $15 \pm 4$ & $9-26$ & $21 \pm 5$ & $12-34$ & $22 \pm 4$ & $14-31$ & $58 \pm 12$ & $40-87$ \\
\hline Clouvas et al. ${ }^{(4)}$ & 60 & $13 \pm 3$ & $9-22$ & $20 \pm 3$ & $12-31$ & $23 \pm 4$ & $14-35$ & $56 \pm 9$ & $41-80$ \\
\hline Clouvas et al. ${ }^{(9)}$ & 225 & $15 \pm 4$ & $5-28$ & $21 \pm 5$ & $6-36$ & $23 \pm 5$ & $5-35$ & $59 \pm 13$ & $18-99$ \\
\hline
\end{tabular}

reported $^{(1)}$ for Central and North European countries, and much smaller than other South European countries like Italy $\left(12 \mathrm{~Bq} \mathrm{~m}^{-3}\right)$.

Although measurements of thoron in indoor air are limited, most investigations have reported both the radon and thoron EECs, so some generalisations for the derived ratios can be made ${ }^{(1)}$. In the present work, from the simultaneous measurement of radon and thoron progeny, the aforementioned ratio could be deduced.

In Figure 7 the frequency distribution of the ratio $\mathrm{EEC}_{\text {thoron }} / \mathrm{EEC}_{\mathrm{Rn}}$ measured in the 26 dwellings is shown.

The mean equilibrium equivalent thoron to radon ratio concentration, measured in the 26 dwellings, is $0.1 \pm 0.06$. This value is higher than the mean ratio $(0.01-0.05)$ reported $^{(1)}$ for Central and North European countries and comparable with other South European countries like Italy (0.11). The fact that the measured ratio is higher than other
European countries is simply due to the fact that the indoor radon and, consequently, the equilibrium equivalent radon concentration, measured in the present work, is small compared with the values usually measured in dwellings of Central and Northern European countries.

\section{Gamma spectrometry measurements}

The mean indoor absorbed gamma dose rates in air, owing to the uranium series, thorium series, ${ }^{40} \mathrm{~K}$ and the sum of them (total), as well as their corresponding minimum and maximum values are presented in Table 1 . The results deduced previously ${ }^{(4,9)}$ from 285 $(225+60)$ indoor gamma spectrometry measurements, performed in Thessaloniki, are presented in the same table. The impressively good agreement between the results of the three datasets, may indicate that for the town of Thessaloniki $(\sim 1$ million inhabitants), about 30 dwellings are enough, in 


\section{A. CLOUVAS ET AL.}

order to have a representative mean value of indoor gamma dose rates.

The mean total absorbed dose rate in air due to gamma radiation is $58 \pm 12 \mathrm{nGy} \mathrm{h}^{-1}$. The contribution of the different radionuclides to the total indoor gamma dose rate in air is $38 \%$ due to ${ }^{40} \mathrm{~K}, 36 \%$ due to thorium series and $26 \%$ due to uranium series.

As the indoor gamma dose rates originate mostly from radionuclides in building materials and as building materials is the main source term ${ }^{(11)}$ for indoor $\mathrm{EEC}_{\text {thoron }}$ and gamma dose rates owing to thorium series. Our results indicate that no such correlation exists. The thoron EEC depends also on the ventilation rate in the building and the exhalation rate of thoron from the walls and floors, which depends very much on the way the surface has been covered with materials which let the thoron pass through. Eventually, if we had performed the measurements at apartments with identical ventilation and surface covers, but different thorium series activity, the correlation would be observed.

\section{Effective dose}

Despite the relative short period of the measurements, it is interesting to estimate the annual effective dose owing to the different source terms (radon, thoron and external gamma radiation). The indoor occupancy factor $(7000 \mathrm{~h})$ and the different conversion factors for radon $\left(9 \mathrm{nSv}\right.$ per $\mathrm{Bq} \mathrm{h} \mathrm{m} \mathrm{h}^{-3}$ ), $\mathrm{EEC}_{\text {thoron }}\left(40 \mathrm{nSv}\right.$ per $\mathrm{Bq} \mathrm{h} \mathrm{m} \mathrm{m}^{-3}$ ) and external gamma radiation $\left(0.7 \mathrm{~Sv} \mathrm{~Gy}^{-1}\right)$ were obtained from UNSCEAR $^{(1)}$. The annual effective dose due to the different source terms are given by the following expressions:

$$
\begin{aligned}
& \text { Radon: } 34 \mathrm{~Bq} \mathrm{~m}^{-3} \times 0.49 \times 7000 \mathrm{~h} \\
& \quad \times 9 \mathrm{nSv} \text { per Bq h m} \mathrm{m}^{-3}=1.05 \mathrm{mSv} . \\
& \text { Thoron: } 1.38 \mathrm{~Bq} \mathrm{~m}^{-3} \times 7000 \mathrm{~h} \\
& \quad \times 40 \mathrm{nSv} \text { per Bq h m} \mathrm{h}^{-3}=0.39 \mathrm{mSv} \\
& \text { Gamma radiation: } 58 \mathrm{nGy} \mathrm{h}^{-1} \times 7000 \mathrm{~h} \\
& \quad \times 0.7 \mathrm{~Sv} \mathrm{~Gy}^{-1}=0.28 \mathrm{mSv}
\end{aligned}
$$

\section{CONCLUSIONS}

Radon gas was measured in each of the 26 dwellings, every $10 \mathrm{~min}$, for a time period between 7 and $10 \mathrm{~d}$. Most of the values of radon gas concentration are between 20 and $30 \mathrm{~Bq} \mathrm{~m}^{-3}$ with an arithmetic mean of $34 \mathrm{~Bq} \mathrm{~m}{ }^{-3}$. The maximum measured value of radon gas concentration is $516 \mathrm{~Bq} \mathrm{~m}^{-3}$. The comparison between the radon gas measurements performed with AlphaGUARD and short-term electret ionisation chamber is very good, taking into account the relative short time period of the measurement and the relative low radon gas concentration.
The mean value of the equilibrium factor $F$ is $0.49 \pm 0.10$, close to the value $0.47 \pm 0.09$ measured previously ${ }^{(3)}$ and close to the typical value of 0.4 adopted by UNSCEAR ${ }^{(1)}$. The distribution of the equilibrium factor, shown in Figure 4, is probably representative for the town of Thessaloniki.

The mean equilibrium equivalent thoron concentration, measured in the 26 dwellings, is $\mathrm{EEC}_{\text {thoron }}=$ $1.38 \pm 0.79 \mathrm{~Bq} \mathrm{~m}^{-3}$. The mean equilibrium equivalent thoron to radon ratio concentration, measured in the 26 dwellings, is $0.1 \pm 0.06$. The fact that the measured ratio is higher than other European countries is simply due to the fact that the indoor radon and, consequently, the equilibrium equivalent radon concentration, measured in the present work, is small compared with the values usually measured in dwellings of Central and North European countries.

The mean total absorbed dose rate in air, owing to gamma radiation, is $58 \pm 12 \mathrm{nGy} \mathrm{h}^{-1}$. The contribution of the different radionuclides to the total indoor gamma dose rate in air is $38 \%$ due to ${ }^{40} \mathrm{~K}, 36 \%$ due to thorium series and $26 \%$ due to uranium series. The impressively good agreement, between the results of the present work with those measured previously ${ }^{(4,9)}$, may indicate that for the town of Thessaloniki ( $\sim 1$ million inhabitants), about 30 dwellings are enough, in order to have a representative mean value of indoor gamma dose rates.

No correlation was observed between indoor $\mathrm{EEC}_{\text {thoron }}$ and gamma dose rates owing to thorium series. Eventually, if we had performed the measurements at apartments with identical ventilation and surface covers, but different thorium series activity, the correlation would be observed.

The annual effective dose due to the different source terms (radon, thoron and external gamma radiation) is $1.05,0.39$ and $0.28 \mathrm{mSv}$, respectively. This means that thoron source term is as much as important as external gamma radiation and therefore must be studied more extensively in the future surveys.

\section{REFERENCES}

1. United Nations Scientific Committee on the Effects of Atomic Radiation. Sources and effects of ionizing radiation. Report to the General Assembly with Scientific Annexes (NY: UN) (2000).

2. Nikolopoulos, D., Louizi, A., Koukouliou, V., Serefoglou A., Georgiou, E., Ntalles, K. and Proukakis, Ch. Radon survey in Greece-risk assesment. J. Environ. Radioact. 63, 173-186 (2002).

3. Clouvas, A., Xanthos, S. and Antonopoulos-Domis, M. Long term measurements of radon equilibrium factor in Greek dwellings. Radiat. Prot. Dosim. 103, 269-272 (2003).

4. Clouvas, A., Xanthos, S. and Antonopoulos-Domis, M. A combination study of indoor radon and in situ gamma 


\section{RADON, THORON AND GAMMA MEASUREMENTS IN GREEK DWELLINGS}

spectrometry measurements in Greek dwellings. Radiat. Prot. Dosim. 103, 363-366 (2003).

5. Kotrappa, P., Dempsey, J. C., Hickey, J. R. and Stieff, L. R. An electret passive environmental ${ }^{222} \mathrm{Rn}$ monitor based on ionization measurement. Health Phys. 54, 47-56 (1988).

6. George A. C. State of the art instruments for measuring Radon/Thoron and their progeny in dwellings - a review. Health Phys. 70, 451-463 (1996).

7. Martz, D., Holleman, D., McCurdi, D. and Schiager, K. Analysis of atmospheric concentrations of $R a A, R a B$ and $R a C$ by alpha spectroscopy. Health Phys. 17, 131-138 (1969).

8. Clouvas, A., Xanthos, S. and Antonopoulos-Domis, M. Derivation of indoor gamma dose rate from high resolution in situ gamma ray spectra. Health Phys. 79, 274-281 (2000).

9. Clouvas, A., Xanthos, S. and AntonopoulosDomis, M. Extended survey of indoor and outdoor terrestrial gamma radiation in Greek urban area by in situ gamma spectrometry with portable Ge detector. Radiat. Prot. Dosim. 94, 233-246 (2001).

10. Usman, S., Spitz, H. and Lee S. Analysis of electret ion chamber detector response to ${ }^{222} \mathrm{Rn}$ and interference from background gamma radiation. Health Phys. 76, 44-49 (1999).

11. European Commission. Radiation Protection Unit, Radiological protection principles concerning the natural radioactivity of building materials. Radiat. Prot. 112 (1999). 